\title{
Editorial
}

\section{A gentle revolution in the world of academic publication}

\author{
Hassen Chaabani \\ Editor-in-Chief
}

In the early 1990s, the idea of online open access to scientific information was emerged owing to the simultaneity of two main phenomena; one represents the cause and the other the solution:

- The cause concerns mainly the dramatic increase in subscription fees of academic journals in their classic print version. In addition the relatively small number of scientific journals has not been evolved sufficiently towards the significant increase of the submitted research works. Hence the publishing process was become more and more slow.

- The solution is provided by the Internet development that would permit, among other things, the possibility to work out an electronic version of scientific journals allowing an international broadcast much cheaper and faster than that provided by the classic print version.

Thus since the 1990s we began to see the appearance of some journals in electronic version "online open access" encouraged by many statements and positions crowned by the appeal made at the 2002 Congress of Budapest the text of which, known as the Budapest Open Access Initiative (BOAI) and supported by the Berlin Declaration in 2003, defines two key strategies:

- The Green Road or Green Open Access strategy concerns the self-archiving of publications by researchers: an author freely online puts its own work on "archives" created for this purpose by institutions. 
- The Gold Road or Gold Open Access strategy concerns the publication of articles in open access journals. Here I will present this strategy showing how it represents a real gentle revolution in the world of academic publication.

\section{Open Access Models of academic journals}

Several models of open access in the Gold Road were invented by the editors. Before presenting some of these models, I would rather present the definition of an open access journal: it is a scientific journal where only peer-reviewed articles that meet good standards are accepted for publication online. However generally we add the term "free" for speaking about "free open access journals". This is not accurate because the expression "free open access journals" means clearly "gratis open access", while as I will present in the following most journals demand charge towards the author or the reader. The most practiced models could be presented as follows:

- The sponsor-pays open access model: it is a free open access model for authors and readers, which represents the real Golden Road desired by all researchers and the public (no publication charge for authors neither consultation charge for readers). The financing of these journals is supported by a sponsor such as a scientific society, a research organization or a foundation.

- The reader-pays open access model: practiced by journals where the author published without fee, but access to published articles is paid by the reader or by his institution.

- The author-pays open access model: following this model the author (or his institution) must pay article processing charges, while the consultation by his peers in open access is free.

- The Hybrid model: it concerns hybrid open choice journals in which the author can choose between two modes of dissemination of his article: either (1) he does not pay anything, but the reader pays, or (2) he pays the article processing charges, while the reader find this article in gratis open access. Hence the editor-publisher retrieves the cost either from the author or the reader. This model is often applied by classic print journals that although become also electronic they continue to accomplish the print version sold within subscriptions; namely in this case the editor-publisher is paid twice for the diffusion of the same articles. 


\section{A real gentle revolution}

As stated above from 1990s the increase of the charge of scientific journals in their classic print version and the insufficient number of these journals in the one hand and the progression of the Internet technology on the other hand were the first start points of a simple evolution from classic print system of academic publication to an electronic system. But I believe that this simple evolution was developed under a snowball effect in a real gentle revolution with its new peculiar problems and consequently new objectives (neo-objectives) (Chaabani 2015). However the transitional period of this revolution seems to be very long because (1) the first objective of start is not yet fully reached: although the number of emerged open access journals has growth dramatically and anarchically at the level that it now exceeds the need, the majority of these journal are not gratis, and (2) the neo-objectives are still far off. Hence, I think that this 25-year transition period (1990 - 2015: first phase) may be extended, at least, for another 25 years (2016 - 2040: second phase). So now we are at the core of this transitional period.

\section{Neo-objectives of the revolution}

During the first phase of transition period new problems have been emerged and some previous problems have been evocated in a revolutionary way. The eventual solutions of these problems represent the neo-objectives of the revolution. I can present these new problems as follows:

\section{Principal emerged problems and corresponding eventual solutions}

- Appearance of high strange coasts of open access research publishing: Several journals particularly in the case of the author pays require high coasts (sometimes the charge exceeds \$2,500 USD per article). These high coasts must be thwarted directly during the debates and statements and indirectly by creating projects, within each country and at the international scale, providing a free open access for readers and a gratis publication for authors or a payment of very low cost tolerated by the community scientific of the different world countries. This will ensure the democratization of knowledge, a better visibility and citability of research works and consequently a 
greater research impact. Hence, we begin to hear about new models of open access journals so-called economic: they are either free or with a low publication charge of about \$100 DA per article.

- Appearance of publishers so-called "predators".

Another problem emerges during this transition period refers to the appearance of some journals created primarily to "make money" and therefore gives no importance to the scientific quality. Thus we must beware of this kind of journals and unveil their publishers so-called "predators".

\section{Evocation of the Impact Factor subject in a revolutionary way}

The traditional journal quality has been assessed through the Thomson Reuters Impact Factor (TRIF). During the present revolutionary transition period this TRIF has been deeply and severely criticized at a level that some journals began to apply other alternative systems meanwhile the scientific community ménages to elaborate a more adequate international system for assessing journals or articles. The principal weaknesses of the TRIF could be summarized as follows:

The TRIF is a journal metric not qualified to assess an article: it expresses the frequency of citation of all articles published in a journal for a definite period. Hence, an article published in a high impact journal may have a number of citations very low, or even zero, and vice versa. This critic is strongly supported by statistical analyses which, in addition, highlighted other problems with the impact factor calculation (e.g., Seglen 1992; Vanclay 2012). In fact, some secondary details in the arithmetic procedure are not publicly available and consequently commercial negotiations with Thomson Reuters often occurred in the aim to vary the TRIF values (for review see PLoS Medicine Editors 2006; Rossner et al. 2007). The strange correlation between the high coasts demanded by some open access journals and their relatively high impact factors could be due to this type of negotiations.

The TRIFs are calculated using citations not only from research articles but also other article categories particularly review articles which tend to receive much more citations than research articles and hence journals carrying some review articles, and especially journals exclusively devoted to them, will have relatively higher TRIFs. In addition, journals in rapidly changing and growing fields such as molecular biology generally have much higher immediate citation rates, so they will always have higher impact factors than those in other fields. 
The TRIFs is calculated annually as the mean number of citations after only two years of published articles. This period of two years cannot be an adequate general period: In fact the results of experimental research works often represent relatively immediate citations during some years generally exceed two years and the peak could be reached within or after these two first years; while the theoretical research works particularly the working out of hypotheses, theses or theories often may reach peak citation many years after their publication, sometimes even after the death of the authors. My recent work (Chaabani 2014), moderately cited (three times) during 2015, would represent a typical example of such theoretical research work that could have a very high peak citation after an unknown numbers of years.

Usually each journal could receive its first impact factor only three years after its acceptation for coverage in one of citation indices of Thomson Reuters. But this acceptation needs a wait of several years often more than a dozen of years in the case of absence of negotiations. In fact, the Thomson Reuters editorial staff has been flood by the requests of several thousands of new open access journals and if they arrive to review a part of them only a low percentage could be accepted for coverage. In addition, although the selection criteria of this coverage acceptance seem theoretically reasonable, it would be uncertain in the practice. Hence, currently several new open access journals refuse the very long wait of Thomson Reuters coverage and the weaknesses of the TRIF and begin to make a self-assessment of their journal. In other words they have ruptured the dictatorship of the single international impact factor "TRIF"

\section{Other evocated subjects}

Other relatively secondary subjects were also evocated such as the priority given to peer-review by some journals following a new model "Peer Journal" giving importance to the reviewers who although have done a great work they are neither paid nor cited. Thus these journals are begun to cite the reviewers and even, if they accept, to publish their comments with the corresponding article. Thus it is a first step that will lead to the fact that only experts can assess an article and not the TRIF of the journal. Finally another subject was evocated concerning the fact that authors would retain all their rights. 


\section{A journal example}

As example I present our journal "International Journal of Modern Anthropology" which has been founded in 2008 (during the first phase of the revolution). It is in accordance with international standards of scientific journals (see details in its site: www.ata.org.tn). It is free for readers and authors, but has not a real sponsor. In fact the only material help that the Tunisian Association of Anthropology (TAA) has presented to our journal is its Web hosting, because the TAA is often in financial difficulty. Therefore our journal represents a very particular model: Can I say that it is a model of volunteering or rather of voluntarism?

Now our journal has successfully passed the first stage by arriving to maintain its stability, the quality of the articles, its technical quality, its internationalization, standardization and transparency: It was indexed and included in more than 25 international database indexing (such as:, African Journals Online "AJOL", Directory of Open Access Journals (DOAJ), Anthropological Literature, and Index Copernicus International), but it is not yet accepted for coverage by Thomson Reuters!!!

\section{Conclusion}

A gentle revolution in the world of academic publication was started since 1990s as a simple evolution from classic print system of academic publication to an electronic system. But this simple evolution was developed under a snowball effect in a real gentle revolution with its new peculiar problems. The first principal new problem lies in the fact that the number of emerged open access journals has growth dramatically and anarchically at the level that now it exceeds the need. In addition, the majority of these journals are not gratis for both readers and authors and high strange coasts of open access research publishing begin to appear often in a strange correlation with a relatively high TRIF. The second principal problem concerns the TRIF itself which suffers so many weaknesses and in any case it cannot tell us anything about the real quality of any original (research) article. The 25-year transition period (1990 - 2015) may be extended for another 25 years period during it the community scientific must find radical resolutions to these two principal problems and other secondary problems. In other words it is time to get things on track in a better way such as the establishment 
of a new international system of journal coverage (indexation) with practical scientific criteria publicly available and particularly the development of a new better way to assess the scientific articles. In any case the dictatorship of the single international impact factor "TRIF" have been ruptured and cannot continue as before because I believe that the revolution is there and we cannot set back the clock.

\section{References}

Chaabani H., 2014. Recent out of Yemen: new version of the theory of unique and recent origin of modern man. International Journal of Modern Anthropology, 7: 13 42.

Chaabani H., 2015. Lecture: Actualités et perspective du libre accès aux revues scientifiques. Journée d'Etude sur le Libre Accès (JELA) 10 Avril 2015, Cité des Sciences, Tunis, Tunisia.

PLoS Medicine Editors. 2006. The Impact Factor Game. PLoS Medicine 3 (6): e291.

Rossner M., Van Epps H. and Hill E. 2007. Show me the data. J Cell Biol 179: 10911092.

Seglen P.O., 1992. Journal impact: How representative is the journal impact factor? Research Evaluation 2: 143-149.

Vanclay J.K., 2012. Impact Factor: outdated artefact or stepping-stone to journal certification?

Scientometrics DOI 10.1007/s11192-011-0561-0

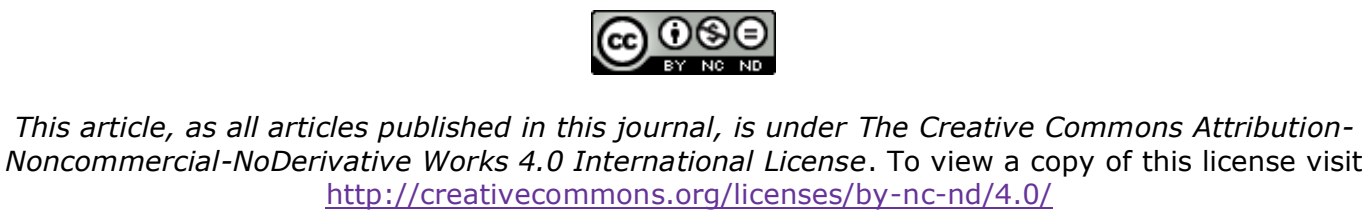
http://creativecommons.org/licenses/by-nc-nd/4.0/ 